\title{
Is there improvement in renal function in patients undergoing bariatric
} surgery?

\section{Juliana Amaro Borborema Bezerra ${ }^{1}$, Carlos Teixeira Brandt ${ }^{2}$, Daniel Mozart Bezerra Borborema ${ }^{3}$, Arthur Quirino Ramos ${ }^{3}$, Matheus Rodrigues de Souza ${ }^{3}$ and Fernanda Andréa Menezes Florêncio Maciel ${ }^{4}$}

${ }^{1}$ Lecturer, Nephrology, Faculty of Medical Sciences, UNIFACISA, Campina Grande, Paraíba, Brazil ${ }^{2}$ Scientific Director, UNIFACISA, Campina Grande, Paraíba, Brazil

${ }^{3}$ Medical Student, UNIFACISA, Campina Grande, Paraíba, Brazil

${ }^{4}$ Nutritionist, Institute of Surgery, Obesity and Endoscopy of Paraíba, Campina Grande, Paraíba, Brazil

\section{Abstract}

Introduction: Obesity may cause progressive chronic kidney disease. Weight loss in the postoperative follow-up of bariatric surgery may improve renal function in these patients. Thus, the purpose of this study was to give insight on the subject using a sensible biomarker.

Methods: This cross sectional study was performed in the Obesity Department from Campina Grande - Paraiba, Brazil. It was randomly enrolled 23 postoperative patients ( 7 bypass and 16 sleeve), with at least two years of follow-up, from the outpatient Department and 29 (18 bypass and 11 sleeve) in the preoperative period for bariatric surgery. They were homogeneously from both genders with ages ranging from 25 to 57 years. Serum levels of creatinine and cystatin $C$ were measured, and the glomerular filtration rate (GFR) was estimated using the CKD Epi (chronic kidney disease epidemiology collaboration) cystatin-creatinine equation. The investigation was approved by the Ethics Committee.

Results: The mean body mass index (BMI) of the preoperative group was significantly greater than the postoperative group $(p \leq 0.0001)$. The mean serum levels of $C$ cystatin was significantly greater in the postoperative group as compared to preoperative $(p=0.0197)$. However, there was no mean difference between creatinine serum concentrations comparing the two groups $(p=$ $0.3252)$. The mean glomerular renal function rates of the groups were similar $(p=0.1240)$.

Conclusion: There is no definitive evidence for supporting the hypothesis that there is improvement in the kidney renal function after bariatric surgery in obese patients. Prospective cohorts are necessary to enlighten the answer for this important question.

\section{More Information}

*Address for Correspondence: Carlos Teixeira Brandt, Rua Felix de Brito 202. Edificio Giulia Priori. Apartamento 3802, Boa Viagem, Recife Pernambuco, Brazil, CEP: 51-20-260, Tel: 5581 999765520; Email: carlosbrandt@bol.com.br

Submitted: 16 July 2019

Approved: 30 July 2019

Published: 31 July 2019

How to cite this article: Bezerra JAB, Brandt CT, Borborema DMB, Ramos AQ, de Souza MR, et al. Is there improvement in renal function in patients undergoing bariatric surgery? J Clini Nephrol. 2019; 3: 143-147.

doi: 10.29328/journal.jcn.1001039

Copyright: @ 2019 Bezerra JAB, et al. This is an open access article distributed under the Creative Commons Attribution License, which permits unrestricted use, distribution, and reproduction in any medium, provided the original work is properly cited

Keywords: Obesity; Kidney function tests; Glomerular filtration rate; Bariatric surgery

Check for updates

\section{Introduction}

Obesity, a serious global public health problem, is due to unhealthy habits and lifestyle, bringing health problems such as diabetes mellitus, hypertension, cardiovascular diseases (CVD) as well as kidney disease [1-3]. The mechanisms of renal dysfunction in obese patients are not entirely clear, although inflammation, oxidative stress and hyper activation of the renin-angiotensin-aldosterone system and / or the sympathetic system, induced by the increase in fat mass, may play a predominant role, besides recruiting functional renal reserve with glomerular hyper filtration. Obesity may promote hypo filtration and is an isolated risk factor for the development of chronic kidney disease (CKD) [4-9].

In an attempt to reduce and slow down the onset and development of obesity and its manifestations, as well as improve quality of life of these individuals, treatment strategies have been used since lifestyle modifications, medications as well as surgical interventions. In this context, bariatric surgery is proposed as one of the treatments for obese patients, with evidence of control of associated comorbidities [10-14].

The effect of bariatric surgery on renal function has been 
investigated and, in some studies, improvement of the glomerular filtration rate (GFR), reduction of hyper filtration and reduction of microalbuminuria can be observed, preventing the onset of CKD and its progression [15-28]. However, there is no agreement on this issue [29]. Therefore more research is needed to be done to make the evidence more consistent.

The purpose of this study was to evaluate the impact of bariatric surgery on renal function of the patients through a more sensitive biological marker.

\section{Methods}

An observational, cross sectional and analytical study was performed. The patients who participated in the study signed an informed consent form (TCLE), after approval of the study by the Ethics Committee of the Faculty of Medical Sciences Campina Grande-Paraíba, Brazil.

The criteria for performing bariatric surgery followed the recommendation of the National Consensus of Health Institutes with body mass index (BMI) $\geq 40 \mathrm{~kg} / \mathrm{m}^{2}$ without comorbidities or $\geq 35 \mathrm{~kg} / \mathrm{m}^{2}$ associated with comorbidities. BMI was obtained by weight, in kilograms, divided by height, by meter squared, and classified according to the values established by the World Health Organization (WHO) [8].

It was randomly enrolled 23 patients who underwent bariatric surgery ( 7 bypass and 16 sleeve) with follow-up of, at least two years and 29 patients in the preoperative period of bariatric surgery (18 bypass and 11 sleeve) with ages between 25 and 57 years. Those who declared themselves to be carriers of renal disease, as well as those with thyroid disease, were excluded from the study [30].

The weight was measured using Tanita $\mathrm{BC} 533^{\circledR}$ portable scale (Brazil), with the patient standing and barefoot, in light clothes and without props. Height was measured by Alturaexata $^{\circledR}$ (Brazil), with the subject standing, barefoot, with heels together, back straight and arms extended at the side of the body.

Blood samples were collected in the morning after a fasting period of at least 12 hours.

The creatinine dosage was performed by the Jaffé reaction, with a result expressed in $\mathrm{mg} / \mathrm{dl}$, from the IDMS (isotope dilution mass spectrometry) methodology, according with organizations involved with laboratory quality management programs, for monitoring of total analytical error linked to the method [31].

The cystatin $\mathrm{C}$ was measured by nephelometry and later calibrated to most recente cystatin $\mathrm{C}$ standardization, with a result expressed in $\mathrm{mg} / \mathrm{L}$ [9].

The estimated glomerular filtration rate (GFR) was calculated using Nefrocalc 2.0 through the CKD-EPi equations cystatin-creatinine. After the calculation of the GFR, a correction was made for the corresponding body surface [8]. It was defined normal GFR between 120 and $90 \mathrm{~mL} / \mathrm{min} / 1.73$ $\mathrm{m}^{2}$, hyper filtration was defined by GFR $>120 \mathrm{~mL} / \mathrm{min} / 1.73$ $\mathrm{m}^{2}$, and GFR hypo filtration $<90 \mathrm{~mL} / \mathrm{min} / 1.73 \mathrm{~m}^{2}$ [6,32-34].

The adjustment for body surface was made as follows:

a) Calculation of BSA (body superficial area), Weight.425 $(\mathrm{kg}) \times$ Height.725 $(\mathrm{cm}) \times .007184$ [5]

b) Adjustment to standard BSA, mGFR (mL/min) $\times 1.73$ / $\operatorname{BSA}\left(\mathrm{m}^{2}\right)=\operatorname{mGFR}\left(\mathrm{mL} / \mathrm{min} / 1.73 \mathrm{~m}^{2}\right)[5]$.

c) De-adjustment from standard BSA, eGFR (mL/min $/ 1.73$ $\left.\mathrm{m}^{2}\right) \times$ BSA $\left(\mathrm{m}^{2}\right) / 1.73 \mathrm{~m}^{2}=\mathrm{eGFR}$ in $\mathrm{mL} / \mathrm{min}[5]$.

The samples were gathered at random from the obesity outpatient department when they were either coming for follow-up or in the preoperative period.

Quantitative variables were expressed by their means and standard deviation. Qualitative variables were expressed by their absolute and relative frequencies. These parameters were fed into excel spreadsheets, and then analyzed using GraphPad InStat3 software.

The Student's t test was used for assessing difference between means. Fisher exact test was used to evaluate possible differences between frequencies.

$\mathrm{p} \leq 0.05$ was established for rejection of the null hypothesis.

\section{Results}

In the preoperative group nine patients were males and 20 were females, the age ranged from 25 to 57 years, mean age $39.5 \pm 8.9$, median was 39 years. In the postoperative group the age range was from 29 to 54 years; the mean age was $38.6 \pm 8.1$, median was 36 years. There was no difference between the two mean ages $(p=0.6185)$. Similarly, there was no difference regarding to gender. In the postoperative group there were 10 males and 13 females $(p=0.3969)$.

The body mass index (BMI) of the pre-operative group was significantly greater than the post-operative group (preoperative - mean: $40.7 \pm 6.6$ versus post-operative group $27.4 \pm 3.0-$ Student' t test $=9.512-\mathrm{p} \leq 0.0001$ ) .

In the preoperative sample (29 patients), 10 had controlled blood hypertension and 10 had diabetes. All of them were receiving medication and apt to major surgery. In the postoperative sample (23 patients) one was bearer of diabetes and two had controlled hypertension. Patients with no comorbidities were 15 out of 29 patients (preoperative); and 20 out of 23 (postoperative) respectively - $(p=0.0086)$.

The mean serum levels of C cystatin was significantly greater in the postoperative group as compared to preopera- 
tive (postoperative $-0.85 \pm 0.22$ versus preoperative $0.73 \pm$ 0.09 - Student' t test $=2.409 \mathrm{p}=0.0197$ ). However, there was no mean difference between creatinine serum concentrations comparing the two groups (postoperative $-0.84 \pm 0.11$ versus preoperative $0.87 \pm 0.13-$ Student $^{\prime} \mathrm{t}$ test $=0.9936 \mathrm{p}$ $=0.3252$ ).

The mean glomerular renal function rates of the groups were similar (postoperative $-107.7 \pm 12.1$ versus preoperative $-118.4 \pm 31.0$ - Student' t test $=1.565 \mathrm{p}=0.1240$ ).

\section{Discussion}

According to the literature, bariatric surgery is the best strategy for obesity with regard to effective and sustained weight loss. One can observe in this study, through the analysis of homogeneous samples for age and sex, a mass index significantly lower in the postoperative group $[12,13,35,36]$.

Studies have pointed the improvement of renal function after bariatric surgery, either with increased glomerular filtration rate in patients with chronic kidney disease [37], or reduction of hyper filtration in patients with no evidence of kidney disease $[15,16,19]$. However, in some studies the sample is too small and in others the biomarkers presents low sensitivity $[17,18]$. Additionally, in other studies, the follow-up is too short. Furthermore, in the majority of the studies, the renal function estimation uses less precise equations [20-24,33].

The literature suggests that the use of markers that suffer less interference due to loss of muscle mass, such as cystatin $\mathrm{C}$, may be a better and more reliable alternative for estimating renal function in patients who lose weight sharply, especially when at the same time uses cystatin $C$ and creatinine by CKD Epi, based on this evidence the analysis of the present study $[27,34,37]$.

There was a significant increase in the level of cystatin $\mathrm{C}$ in the post-bariatric group, but there was no difference between the two groups in relation to the serum creatinine concentration, which is in contrast to what is found in the literature, in order to observe reduction of creatinine levels due to loss of muscle mass in most studies. Regarding cystatin $\mathrm{C}$, the studies point to an unchanged dosage in the postoperative period of bariatric surgery, and in some cases, even with increased levels of cystatin $C$, which does not mean changes in the glomerullar renal filtration [38,39].

In this study, no statistically significant difference was observed in relation to the glomerular filtration rate when compared to the pre and post-bariatric surgery groups, corroborating other studies that do not evidence the effect of bariatric surgery on the improvement of renal function. On the other hand, some even suggest a worsening of the renal function after the surgical approach [28,29,40,41]. Thus, adding cystatin $C$ for increasing sensitivity and specificity for better use of renal function equations did not give evidence for supporting improvement of renal function after bariatric surgery in obese patients.

As regard to comorbidities (blood hypertension and diabetes) it seems that the prevalence of these diseases decreased significantly after bariatric surgery. However, one needs caution on this statement since the groups were not paired and the research was a cross sectional investigation.

\section{Limitations}

First, the sample sizes of the two groups are too small for definitive evidence on this important question. Second, these samples are unpaired and may represent different biological parameters for the researched variables. Third, the follow-up time of the postoperative group (median 37 months) could be not sufficient for assessing renal function after bariatric surgery in obese patients. Fourth, the frequencies of bariatric surgery types were different between the two groups. Even though, the study has made a contribution for this challenging question - Is there improvement in renal function in patients undergoing bariatric surgery?

\section{Conclusion}

In this study, no statistically significant difference was observed in relation to the glomerular filtration rate when compared the pre and post-bariatric surgery groups, corroborating other studies that did not evidence the effect of bariatric surgery on the improvement of renal function, and some even suggest a worsening of the function after the surgical approach. Further prospective cohorts are required for better answer of the main purpose of this issue.

\section{References}

1. Swinburn BA, Sacks G, Hall KD, McPherson Klim, Finegood DT, et al. The global obesity pandemic: shaped by global drivers and local environments. Lancet. 2011; 378: 804-814. PubMed: https://www. ncbi.nlm.nih.gov/pubmed/21872749

2. Flegal KM, Carroll MD, Ogden CL, Curtin LR. Prevalence and trends in obesity among US adults.1999-2008. JAMA. 2010; 303: 235-341. PubMed: https://www.ncbi.nlm.nih.gov/pubmed/20071471

3. Flegal KM, Carroll MD, Kit BK, Ogden CL. Prevalence of obesity and trends in the distribution of body mass index among US adults, 19992010. JAMA. 2012; 307: 491-497. PubMed: https://www.ncbi.nlm. nih.gov/pubmed/22253363

4. Helal I, Fick-Brosnahan GM, Reed-Gitomer B, Schrier RW. Glomerular hyperfiltration: definitions, mechanisms and clinical implications. Nat Rev Nephrol. 2012; 8: 293-300. PubMed: https://www.ncbi.nlm.nih. gov/pubmed/22349487

5. Favre G, Schiavo L, Lemoine S, Esnault VLM, lannelli A. Longitudinal assessment of renal function in native kidney after bariatric surgery. Surg Obes Relat Dis. 2018; 14: 1411-1418. PubMed: https://www. ncbi.nlm.nih.gov/pubmed/30077663

6. Choi JI, Cho YH, Lee SY, Jeong DW, Lee JG, et al. The Association between obesity phenotypes and early renal function decline in adults 
without hypertension, dyslipidemia, and diabetes. Korean J Fam Med. 2019; 40: 176-181. PubMed: https://www.ncbi.nlm.nih.gov/pmc/ articles/PMC6536908/

7. Chang AR, Surapaneni A, Kirchner HL, Young A, Kramer HJ, et al. Metabolically healthy obesity and risk of kidney function decline. Obesity (Silver Spring). 2018; 26: 762-768. PubMed: https://www. ncbi.nlm.nih.gov/pubmed/29498223

8. Eknoyan G. Obesity and chronic kidney disease. Nefrologia. 2011;31: 397-403. PubMed: https://www.ncbi.nlm.nih.gov/pubmed/21623393

9. Grubbs V, Lin F, Vittinghoff E, Shlipak MG, Peralta CA, et al. Body mass index and early kidney function decline in young adults: A longitudinal analysis of the CARDIA (Coronary Artery Risk Development in Young Adults) study. Am J Kidney Dis. 2014; 63: 590-597. PubMed: https:// www.ncbi.nlm.nih.gov/pubmed/24295611

10. Schauer PR, Bhatt DL, Kirwan JP, Wolski, K, Brethauer AS, et al. Bariatric surgery versus intensive medical therapy for diabetes 3-year outcomes. N Engl J Med. 2014. PubMed

11. Fenske WK, Dubb S, Bueter M, Seyfried F, Patel K, et al. Effect of bariatric surgery- induced weight loss on renal and systemic inflammation and blood pressure: a 12-month prospective study. Surg Obes Relat Dis 2012; 9: 559-568. PubMed: https://www.ncbi. nlm.nih.gov/pubmed/22608055

12. Ovrebo B, Strommen $M$, Kulseng B, Martins $C$. Bariatric surgery versus lifestyle interventions for severe obesity: 5-year changes in body weight, risk factors and comorbidities. Conservative and surgical treatment of obesity. Cli Obes. 2017.

13. Borisenko O, Mann O, Duprée A. Cost-utility analysis of bariatric surgery compared with conventional medical management in Germany: a decision analytic modeling. BMC Surg. 2017; 17: 87. PubMed: https://www.ncbi.nlm.nih.gov/pubmed/28774333

14. Alamuddin N, Bakizada Z, Wadden TA. Management of Obesity. J Clin Oncol. 2016. 34: 4295-4305. PubMed: https://www.ncbi.nlm.nih.gov/ pubmed/27903153

15. Coupaye M, Flamant $M$, Sami $O$, Calabrese D, Msika $S$, et al. Determinants of evolution of glomerular filtration rate after bariatric surgery: a 1-year observational study. Obes Surg. 2017; 27: 126-133. PubMed: https://www.ncbi.nlm.nih.gov/pubmed/27312348

16. Chang AR, Chen Y, Still C, Wood GC, Kirchner HL, et al. Bariatric surgery is associated with improvement in kidney outcomes. Kidney Int. 2016; 90: 164-171. PubMed: https://www.ncbi.nlm.nih.gov/ pubmed/27181999

17. Li K, Zou J, Ye Z, Di J, Han X, et al. Effects of bariatric surgery on renal function in obese patients: A systematic review and meta analysis. PLoS One. 2016; 11: e0163907. PubMed: https://www.ncbi.nlm.nih. gov/pubmed/27701452

18. Ji M, Lee $\mathrm{YH}, \mathrm{Hur} \mathrm{M}, \mathrm{Kim} \mathrm{H}, \mathrm{Cho} \mathrm{HI}$, et al. Comparing results of five glomerular filtration rate-estimating equations in the Korean general population: MDRD study, revised Lund-Malmo, and three CKD-EPI equations. Ann Lab Med 2016; 36: 521-528. PubMed: https://www. ncbi.nlm.nih.gov/pubmed/27578504

19. Clerte $M$, Wagner S, Carette $C$, Brodin-Sartorius A, Vilaine E, et al. The measured glomerular filtration rate (mGFR) before and 6 months after bariatric surgery: A pilot study. Néphrologie \& Thérapeutique. 2017; 13: 160-167. PubMed: https://www.ncbi.nlm.nih.gov/ pubmed/28161263

20. Neff KJ, Frankel AH, Tam FWK, Sadlier DM, Godson C, et al. The effect of bariatric surgery on renal function and disease: a focus on outcomes and inflammation. Nephrol Dial Transplant. 2013; 28(Suppl 4). iv73-iv82. PubMed: https://www.ncbi.nlm.nih.gov/ pubmed/24071659
21. Friedman AN, Moe S, Fadel WF, Inman M, Mattar SG, et al. Predicting the glomerular filtration rate in bariatric surgery patients. Am J Nephrol. 2014; 39: 8-15. PubMed: https://www.ncbi.nlm.nih.gov/ pubmed/24356416

22. Hou CC, Shyu RS, Lee WJ, Ser KH, Lee YC, Chen SC. Improved renal function 12 months after bariatric surgery. Surg Obes Relat Dis. 2013; 9: 202-206. PubMed: https://www.ncbi.nlm.nih.gov/ pubmed/23246320

23. Holcomb CN, Goss LE, Almehmi A, Grams JM, Corey BL. Bariatric surgery is associated with renal function improvement. Surg Endosc. 2018: 32: 276-281. PubMed: https://www.ncbi.nlm.nih.gov/ pubmed/28664440

24. Ritz E. Bariatric surgery and the kidney - Much benefit, but also potential harm. Clin Kidney J. 2013. 6: 368-372.

25. Fenske W, Athanasiou T, Harling L, Drechsler C, Darz A, Ashrafian H. Obesity-related cardiorenal disease: the benefits of bariatric surgery. Nat Rev Nephrol. 2013; 9: 539-551. PubMed: https://www.ncbi.nlm. nih.gov/pubmed/23917797

26. Chang A, Greene TH, Wang X, Kendrick C, Kramer $\mathrm{H}$, et al. The effects of weight change on glomerular filtration rate. Nephrol Dial Transplant. 2015; 30: 1870-1877. PubMed: https://www.ncbi.nlm. nih.gov/pubmed/26085555

27. Inker LA, Schmid $\mathrm{CH}$, Tighiouart $\mathrm{H}$, Eckfeldt JH, Feldman $\mathrm{HI}$, et al. Estimating glomerular filtration rate from serum creatinine and cystatin C. N Engl J Med. 2012; 367: 20-29. PubMed: https://www. ncbi.nlm.nih.gov/pubmed/22762315

28. Chang AR, Grams ME, Navaneethan SD. Bariatric surgery and kidneyrelated outcomes. Kidney Int Rep. 2017; 2: 261-270. PubMed https:// www.ncbi.nlm.nih.gov/pubmed/28439568

29. Chuah LL, Miras AD, Perry LM, Frankel AH, Towey DJ, et al. Measurement of glomerular filtration rate in patients undergoing obesity surgery. BMC Nephrology. 2018; 19: 383.

30. Stojanoski S, Gjorceva DP, Gruev T, Miceva SR, Ristevska N. Impact of thyroid dysfunction on serum cystatin $\mathrm{C}$, serum creatinine and glomerular filtration rate. Maced J Med Sci. 2011; 4: 25-30.

31. Oliveira RB, Kirsztajn GM, Alcântara FFP. Doença renal e calibração da dosagem de creatinina no Brasil: Onde estamos? J Bras Nefrol 2015; 37: 431-432.

32. Gabriel IC, Nishida SK, Kirsztajn GM. Serum cystatin C: a practical alternative for renal function evaluation? J Bras Nefrol 2011; 33: 261267. PubMed: https://www.ncbi.nlm.nih.gov/pubmed/21789445

33. Kumar BV, Mohan T. Retrospective comparison of estimated GFR using 2006 MDRD, 2009 CKD-EPI and Cockcroft-Gault with 24 hour urine creatinine clearance. J Clin Diagn Res. 2017; 11: BC09-BC12. PubMed: https://www.ncbi.nlm.nih.gov/pubmed/28658750

34. Grubb A, Nyman U, Bjork J. Improved estimation of glomerular filtration rate (GFR) by comparison of eGFR cystatin $\mathrm{C}$ and eGFR creatinine. Scand J Clin Lab Invest. 2012; 72: 73-77. PubMed: https://www.ncbi. nlm.nih.gov/pmc/articles/PMC3279136/

35. de Paris FGC, Padoin AV, Mottin CC2, de Paris MF. Assessment of changes in body composition during the first postoperative year after bariatric surgery. Obes Surg. 2019; PubMed: https://www.ncbi.nlm. nih.gov/pubmed/31254214

36. Park JY, HeoY, Kim YJ, Park JM, Kim SM. Long-term effect of bariatric surgery versus conventional therapy in obese Korean patients: a multicenter retrospective cohort study. Ann Surg Treat Res. 2019; 96: 283-289. PubMed: https://www.ncbi.nlm.nih.gov/pubmed/31183332 
37. Imam TH, Fischer H, Jing B, Burchette R, Henry S, et al. Estimated GFR before and after bariatric surgery in CKD. Am J Kidney Dis. 2017; 69: 380-388. PubMed: https://www.ncbi.nlm.nih.gov/ pubmed/27927587

38. Navaneethan SD, Malin SK, Arrigain S, Kashyap SR, Kirwan JP, et al. Bariatric surgery, kidney function, insulin resistance, and adipokines in patients with decreased GFR: A cohort study. Am J Kidney Dis. 2015; 65: 345-347. PubMed: https://www.ncbi.nlm.nih.gov/ pubmed/25458664

39. Sledziński T, Proczko-Markuszewska M, Kaska L, Stefaniak T,
Swierczyński J. Serum cystatin c in relation to fat mass loss after bariatric surgery. Pol J Surg. 2012. 84: 202-207. PubMed: https:// www.ncbi.nlm.nih.gov/pubmed/22698658

40. Scholten BJV, Persson F, Svane MS, Hansen TW, Madsbad S, et al. Effect of large weight reductions on measured and estimated kidney function. BMC Nephrology. 2017; 18: 52.

41. Kim EY, Kim YJ. Does bariatric surgery really prevent deterioration of renal function? Surg Obes Relat Dis. 2016; 12: 856-861. PubMed: https://www.ncbi.nlm.nih.gov/pubmed/26823090 